\title{
Neural Basis of Learning
}

\author{
Bases Neurais da Aprendizagem
}

\section{Elisa Rocha, Beatriz Costa, Isadora Ferreira, Felipe Fregni}

Rocha E, Costa B, Ferreira I, Fregni F. Neural Basis of Learning / Bases Neurais da Aprendizagem. Rev Med (São Paulo). 2018 jan.fev.;97(1):1-6.

\begin{abstract}
Students' learning mechanisms and success are crucial to the advancement of education and knowledge. Therefore, understanding the neural basis of learning and applying it to educational programs can enhance how individuals acquire knowledge. Currently, educational programs are mostly centered on a teacher-based approach, which is not ideal for information retention. Instead, programs should be focused on achieving the three stages of learning: encoding, consolidation, and retrieval. In fact, current methods do not result in significant encoding (the first step). Strong encoding is associated with individual's attention and focus on the material. Consolidation comes from the strengthening of neural pathways by providing meaning to the material being learned, and establishing strong connections to achieve long-term potentiation. Finally, retrieval is maximized when knowledge is fully established and a schema has been attained. It is important to take into account how education influences and can be used to optimize learning. Considering existing neural evidence, educational systems should change to a student-centered approach to improve learning.
\end{abstract}

Keywords: Neuronal plasticity; Education; Learning; Teaching; Long-term potentiation.
RESUMO: O sucesso e os mecanismos de aprendizado dos estudantes são cruciais para o avanço da educação e do conhecimento. Por este motivo a compreensão da base neural relacionada ao aprendizado, bem como a sua aplicação em programas de educação pode aprimorar o modo como os indivíduos adquirem conhecimento. No momento atual, os programas de educação são principalmente centrados em uma abordagem baseada no professor, a qual não é o método ideal para a retenção da informação. Ao invés, os programas deveriam estar focados em alcançar os três estágios de aprendizagem: codificação ("encoding"), consolidação ("consolidation") e recuperação ("retrieval"). De fato, os métodos atuais não resultam sequer em uma significativa codificação (o primeiro estágio). Uma forte codificação está associada com a atenção e foco do indivíduo no material abordado. A consolidação vem do fortalecimento dos caminhos neurais, ao passo em que proporciona significado ao material que está sendo aprendido e estabelece fortes conexões para alcançar a potencialização de longo prazo. Finalmente, a recuperação é maximizada quando o conhecimento é totalmente estabelecido e um esquema alcançado. No geral, é importante levar em consideração como a educação afeta o aprendizado, e como esta pode ser utilizada para otimizá-lo. Levando em consideração a evidência neural existente, os sistemas de educação deveriam adotar uma abordagem centrada no aluno para melhorar a aprendizagem.

Descritores: Plasticidade neuronal; Educação; Aprendizagem; Ensino; Potenciação de longa duração.

Spaulding Neuromodulation Center, Spaulding Rehabilitation Hospital and Massachusetts General Hospital, Harvard Medical School. Emails: Fregni.Felipe@mgh.harvard.edu, https://orcid.org/0000-0002-1703-7526; bcosta@neuromodulationlab.org, https://orcid. org/0000-0001-8915-0985; iferreira@neuromodulationlab.org, https://orcid.org/0000-0002-4709-8952; elisaroc@usc.edu, https://orcid. org/0000-0001-6343-8534.

Correspondence: Felipe Fregni, MD, PhD, MPH. 96 13th Street, Charlestown MA 02129. Email: fregni.felipe@mgh.harvard.edu. 


\section{INTRODUCTION}

$\mathbf{B}_{\text {research, what was previously known about }}^{\text {ased on the rapid advance of neuroscientific }}$ the neural basis of learning has changed and new insights on neuroplasticity are currently being developed. To date, empirical studies on brain network interactions, neuronal connectivity, and brain functions are commonly explored for a better comprehension of the cognitive process involved with learning ${ }^{1}$. Indeed, there is a wide variation among individuals' ability to learn and retain information, however it has been proved that all individuals have one characteristic in common: the learning process is mainly based on making new neural connections. A deeper understanding on how brain circuits connect creates meaningful implications for improving educational programs.

Education is a crucial method to build one's resilience, increase self-awareness, and provide the capacity to constantly improve knowledge. Comprehending how educational programs are designed, as well as making strong efforts to optimize them, are imperative tasks for several professionals ${ }^{2}$. Education programs are currently designed to deliver predefined content to students and establish their learning goals. However, more important than providing expository lectures, the opportunity to help students understand the content and make new brain connections allows them to capture and retain new information. If educators are able to help students build these new connections and activate learning processes in the brain, teaching goals may be satisfactorily achieved ${ }^{2}$.

Primary learning processes are commonly being used in educational programs with the goal of applying gathered scientific evidence in learning environments. Nowadays, most courses are based on a teacher-centered format, which means that teachers focus exclusively on giving lectures and presenting a specific content. In this format, students are not encouraged to participate in their own learning process; they are used to keep receiving information without processing it, which hinders information retention through the creation of new neural connections. Teacher-centered programs do not allow an accurate encoding of information and, as a result, do not promote long lasting knowledge. An additional barrier is that students usually prefer teacher-centered methods because (1) this is usually more comfortable to students because it requires less work from them and (2) it brings the wrong perception that they "learned" more because extra content was provided. Ideally, educational programs should be based on a learner-centered format, in which the focus is shifted from teacher to student. In this format, students become highly engaged in their learning process, also accounting for individual differences and learning styles. Also, discussions and interaction between learners are common in student-centered programs, helping them develop critical thinking and communication skills ${ }^{3}$.

Current knowledge regarding the influence of neuroplasticity and attention on the learning process reaffirms that education should have student focused programs. Although it is known that a student-centered format is important for engaging students to acquire lifelong learning, numerous programs still do not adhere to this format. As a consequence, these programs often fail to guide and teach students effectively. The goal of this article is to provide a brief review of important learning mechanisms to design a new course, also presenting different strategies commonly applied to incorporate these mechanisms in education.

\section{BASIC PRINCIPLES OF NEUROPLASTICITY}

According to Hebb's law, one of the main concepts in neuroscience, which proposes an explanation for the adaptation of neurons during the learning process, "neurons that fire together, wire together"4. Consequently, by firing together through electrical current, neurons wire together, thus promoting structural changes. In addition, neurons can be combined into one processing unit, referred to as "cell-assemblies". Based on these concepts, the enhancement of the communication between circuits allows the brain to form and reorganize synaptic connections, also known as neuroplasticity.

The ability to reorganize by forming new connections counterposes old assumptions that with age the only changes that take place in the brain are negative (e.g. the loss of brain cells with aging), or that an individual can only use a percentage of their brain capacity ${ }^{1}$. By observing an adult brain, it is possible to notice that even at rest the brain is highly active. Also, it is now possible to assume that the learning process leads to positive reorganization in the brain. Whether it is through chemical-induced changes (e.g. increase of neurotransmitters' concentration), by altering its structure or its function, the brain is able to adapt in order to support learning and produce either short-term or longterm knowledge.

After forming new synapses, another important process is consolidation. Among several mechanisms that promote neuroplasticity, two noteworthy ones include long-term potentiation (LTP) and long-term depression (LTD), which are highly related with synaptic strength. ${ }^{4}$ Due to changes in the neuron membrane, caused by either the increase or decrease in the amount of specific neurotransmitters and ions, there can be an increase in the synaptic strength (LTP) or a decrease in the synaptic strength (LTD). During LTP, the synapse is considered "enhanced," while during LTD the synapse is considered "inhibited." These physiological changes are thought to be the mechanisms underlying the expression of LTP and LTD. 


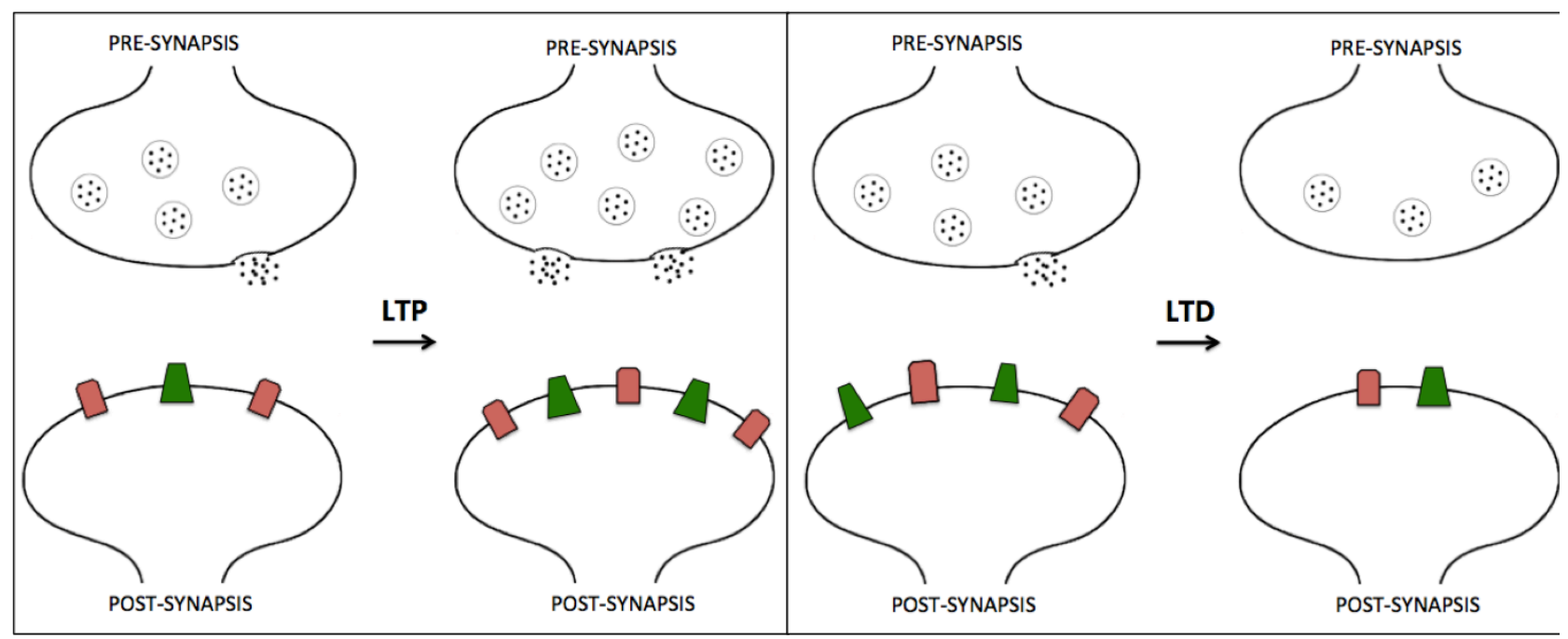

Figure 1. Synaptic mechanisms of long-term potentiation (LTP) and long-term depression (LTD)

\section{How can these principles be applied to education?}

The relationship between all of these neurological aspects and education is evident, since several educational programs often focus on content, thus hindering the development of long-term knowledge. However, learning goes beyond content. It depends on the student's capacity to connect new information with old information, the teacher's capability to become a facilitator of the process, and the student's will to not simply absorb information, but instead understand and store knowledge through the development of new connections between firing neurons. One of the main challenges in education is how to transform short-term knowledge into meaningful learning that results in long lasting effects.

Effective learning comes with the capability for students to create these new neural connections. The learning process is a result of the brain's ability to constantly change and make new connections. However, in order to produce a true impact, these connections should be long lasting. In other words, the student, in order to learn, needs to fire neurons not only from their auditory cortex (meaning they heard the content), but also from other brain areas to connect new content with previous information to truly establish long-lasting learning.

\section{THREE STAGES OF LEARNING: ENCODING, CONSOLIDATION, AND RETRIEVAL}

After understanding the neural mechanisms of how learning occurs, how can one make sure these processes occur in the classroom? There are three major learning stages that an individual must undergo in order to achieve long-term memory: encoding, consolidation, and retrieval. Each step is individually important but also interdependent.
Educators should constantly be aware of whether they want the material they are teaching to be stored as long-term or short-term memory. For example, if an individual is provided with a sequence of numbers (e.g. $1,7,0,2,4,6,9)$, these numbers enter their working memory in the hippocampus. Most likely, when asked to repeat the numbers the next day, the individual will have already forgotten. This is not because the brain has erased this information, but because no meaning was associated with that memory. In order to bring a memory from short to long-term, one must establish meaning through connections. Connecting new material to previous concepts creates a neural network is that allows for easier retrieval of information. The process of bringing learned information from short-term to long-term is called: "consolidation".

Consolidation is known as the progressive stabilization of working memory into long-term memory. During stabilization, a memory is enhanced and integrated into pre-existing areas in the brain to improve its retrieval in the future ${ }^{6}$. There are two types of memory that can be developed during the consolidation period. The first one is "declarative" memory, which is often used for the recollection of specific facts and events that can be consciously recalled on an everyday basis ${ }^{6}$. The second type of memory is "procedural" memory. These are sensory motor behaviors an individual has acquired over time that the human brain recalls unconsciously (e.g. why one never forgets how to ride a bicycle). Both types of memory are extremely important and have to work together during the learning process.

The next learning stage is the retrieval of stored longterm memory. Easy and constant retrieval of information in a specific area is considered the acquisition of a particular schema. A schema is a mental structure consisting of an 
intertwined network of neurons that allows the brain to organize and easily recall obtained knowledge ${ }^{7}$. Acquiring a schema is considered achieving expertise in a particular area. Therefore, when learning new material, a student's goal is to develop new schemas. The schema development process can be achieved through the utilization of longterm memory storage while reducing cognitive load. Decreasing cognitive load can promote schema formation by decreasing both extraneous and intrinsic material when learning. Through the reduction of these forms of cognitive load, the third and most important cognitive load, germane, can be emphasized. Germane allows for the development and automation of important schemas to enhance learning?. This completes the final step of the learning stages, when an individual is able to easily recall information learned over time.

However, before consolidation and retrieval can be effectively obtained, one must begin with a strong foundation for learning, known as the encoding stage of learning. Since working memory is limited, while long-term memory has an unlimited capacity, a specific encoding basis must be established in order to maximize long-term consolidation.

\section{How can these principles be applied to education?}

The process of how long-term versus short-term memories are acquired is important for educators and students to keep in mind when respectively teaching and learning new material. As previously mentioned, educators should be aware of how information retention works to be able to facilitate the learning process. Information ought to be presented in a manner that allows students to establish neural connections while learning the material to enhance memory retrieval. Through this process, students are able to consolidate material learned in class into their longterm memory in order to recall the information at a later time. Furthermore, both educators and students should be conscientious of decreasing extraneous cognitive load to promote optimal schema formation. Here the educator should be concerned not with quantity (of content) but quality of assimilation. In other words, it is better to go through one paragraph over the course of a semester than provide students with three entire books that he or she does not truly process.

\section{ATTENTIONAL SYSTEMS}

The process of encoding new information is the primary step for effective learning. The subsequent steps, consolidation and retrieval, can only be achieved after the development of a strong encoding base. Indeed, the encoding ability of the brain is directly related to the attentional system, as individuals need focus and continuous mental effort for capturing meaningful information. Paying attention involves multiple cognitive processes, each of which is fundamental for learning and understanding ${ }^{8}$. For individuals capable of filtering perceptions, selecting what needs most attention and focus, the learning process is easily built up.

Numerous anatomical structures of the brain collaborate for the maintenance of a competent attentional system. The thalamus, for instance, constantly receives different types of information (i.e. auditory, visual and tactile) from multiple peripheral sensory organs. The thalamus main role is to filter these sensory stimuli, give priority to specific ones, and maintain focus to ensure learning. The frontal lobes are also essential structures involved in the attentional system, as they help the brain to concentrate on important perceptions and increase the duration of attention 9 . Furthermore, a particular formation in the brain stem, called Reticular Activating System (RAS), has an important role in establishing alertness and arousal, which are essential components of attention. This brain region is highly activated during tasks requiring close attention and strong mental energy.

Attention can be subdivided into two distinct forms: passive and active. While passive attention is subconscious and related to involuntary perceptions precipitated by external stimuli, active attention is chiefly guided by voluntary interest and requires alertness and effort ${ }^{10}$. These forms are important in the learning process, but passive attention alone is insufficient. For instance, students in a classroom may automatically concentrate on a lecture, but they need active attention and mental effort to maintain concentration and capture the necessary information. Additionally, attention is driven by different mechanisms denominated as exogenous or endogenous control. The exogenous control, known as the bottom-up mechanism, is stimulus-driven and oriented toward external aspects. The endogenous mechanism, labeled as top-down control, is cognitively driven and based on existing knowledge and intention $^{10,11}$.

\section{How can these principles be applied to education?}

When able to maintain active attention and ensure that the brain is focused on a particular stimulus, learners are well prepared for capturing new information and engaging their attentional system ${ }^{11}$. Accordingly, teachers should catch students' attention by giving a cue before providing any stimuli, such as telling them that they are about to hear something very important. Another aspect of the learning process worth mentioning is that individuals are wired to turn their attention to contrasts, which means that students are encouraged to maintain focus and attention 
when contrasts are incorporated in the situation. ${ }^{12}$ For example, educators who often keep the same tone of voice and do not move during lectures make it easier for students to get distracted. Thus, changing one's tone of voice, illustrating the lecture and making it dynamic are useful strategies to make learners interested in paying attention.

Besides educator's frequent efforts to engage students, learning styles also vary among individuals and can affect their learning performance ${ }^{13}$. Some students may find difficulties following lectures and memorizing concepts, while others may learn better by reading out loud or by visualizing images. These distinct forms of learning may explain why students respond differently to stimuli; however, the structures and functions of the attentional system ultimately determine the capacity of an individual to effectively pay attention and learn. Finally, it is important to engage the endogenous attentional system of students or their top-down mechanisms to enhance their motivation with the material.

\section{DISCUSSION}

Overall, the basis of education and learning systems revolves around the establishment of interneuron connections. Strong connections are created through three stages of learning: encoding, consolidation, and retrieval. The encoding process is optimized by active attention and focus to learn meaningful information. Following encoding, consolidation occurs over a period of time in order to stabilize the information from the working memory into long-term memory by providing meaning. The underlying neurophysiological mechanism is explained through the strengthening of synapses in long-term potentiation. After the development of the schema, as a result of LTP, the easy retrieval of information can be achieved. All three of these stages must occur in order to have adequate learning.

Considering these concepts, education must focus on student-centered techniques that can enhance learning mechanisms. There are a few ways this can be achieved through changes made by both educators and students. One action professors can take to enhance encoding mechanisms is to have shorter lectures, or provide short intervals throughout the class. The changes in stimuli can motivate the students and maintain their attention on the topic at hand throughout the course of the lecture. Another technique that can be used to capture students' attention is live interaction and participation. By prompting the students with questions while changing the pace of the lecture can keep students focused on the material. Finally, in order to achieve successful encoding, students should be given information on the topic before coming to lecture. By exposing students to material beforehand, a neural pathway will be established which will be enhanced and reinforced during the lecture.
In terms of improving the consolidation for students, the most important aspect that should be focused on is making connections. This is the key to developing longterm memory, because "neurons that fire together, wire together". By making connections with previous material, the educator is providing meaning that supports what students are learning, helping them establish a neural network to achieve long-term potentiation for future knowledge retrieval. However, education is not based only on how the material is presented, but also how the material is retained. Without student engagement and motivation, learning cannot be achieved. Students must work with educators to prepare themselves for the content they will learn in lecture through readings and assignments. They must also have the motivation to study the topic. If an individual tries to learn a topic out of obligation and interest, it will significantly impact their encoding abilities.

Education is a balance of educator preparation and presentation with student commitment and motivation. Our current educational systems are based on a teach-centered model, which places the content being learned above the mechanism of learning. A need for change is clearly illustrated through the evidence previously discussed about how an individual learns and retains information. The three steps of learning should be considered and optimized to enhance the retention of information.

\section{CONCLUSION}

In order to achieve meaningful and efficient learning, students should be able to properly combine the neurological network with effective techniques, such as the development of associations between new knowledge and previous knowledge, discussing the content as if it is always extremely important, or combining different methods (visual, auditory or kinesthetic) of learning to enhance the process. Mainly, it is fundamental to comprehend that education and learning are dependent on the development of new connections between neurons.

The current the education process revolves around the teacher instead of the student. The most common techniques used are not always focused in providing tools which facilitate long-term learning. For instance, exposing students to a significant amount of content is often more important than making students acquire a small, but permanent knowledge. Although it may be challenging to change culture, it is crucial that the learning system becomes student-centered instead of teacher-centered.

It becomes clear that changes are required in order to improve education. Similarly, due to the importance of this topic and the limited amount of information regarding the neural basis of learning, additional research studies are necessary. 


\section{REFERENCES}

1. After watching this, your brain will not be the same |Lara Boyd| TEDxVancouver - YouTube. Available from: https:// www.youtube.com/watch? $v=$ LNHBMFCzznE.

2. Brain Waves Module 2: Neuroscience: implications for education and lifelong learning. London: The Royal Society; 2011. Available from: https://royalsociety.org/ /media/Royal_Society_Content/policy/publications/2011/4294975733.pdf.

3. Garrett T. Student-centered and teacher-centered classroom management: a case study of three elementary teachers. J Classr Interact. 2008;43:34-47. Available from: http://files. eric.ed.gov/fulltext/EJ829018.pdf.

4. Kuśmierz $Ł$, Isomura $\mathrm{T}$, Toyoizumi $\mathrm{T}$. Learning with three factors: modulating Hebbian plasticity with errors. Curr Opin Neurobiol. 2017;46:170-7. https://doi.org/10.1016/j. conb.2017.08.020.

5. Pulvermüller F. Hebb's concept of cell assemblies and the psychophysiology of word processing. Psychophysiology. 1996;33:317-33. doi: 10.1111/j.1469-8986.1996.tb01057.x.

6. Robertson EM. New insights in human memory interference and consolidation. Curr Biol. 2012;22(2):R66-R71. https:// doi.org/10.1016/j.cub.2011.11.051.

7. Cognitive Load Theory explained by Dr Majeda A. Caleo Founder of GEA - YouTube. Available from: https://www. youtube.com/watch? $\mathrm{v}=$ pCOYCVBgQWQ.

8. Ratey JJ. A user's guide to the brain : perception, attention, and the four theaters of the brain. New York: Pantheon Books/ Vintage Books; 2001.

9. de Bourbon-Teles J, Bentley P, Koshino S, Shah K, Dutta A, Malhotra P, Egner T, Husain M, Soto D. Thalamic control of human attention driven by memory and learning. Curr Biol. 2014;24:993-9. doi: 10.1016/j.cub.2014.03.024.

10. Center for Development and Learning (CDL). What is attention? Available from: http://www.cdl.org/articles/what-isattention/.

11. Fears SC, Schür R, Sjouwerman R, Service SK, Araya C, Araya X, Bejarano J, Knowles E, Gomez-Makhinson J, Lopez MC, Aldana I, Teshiba TM, Abaryan Z, Al-Sharif NB, Navarro L, Tishler TA, Altshuler L, Bartzokis G, Escobar JI, Glahn DC, Thompson PM, Lopez-Jaramillo C, Macaya G, Molina J, Reus VI, Sabatti C, Cantor RM, Freimer NB, Bearden CE. Brain structure-function associations in multi-generational families genetically enriched for bipolar disorder. Brain. 2015;138:2087-102. doi: 10.1093/brain/awv106.

12. Herrmann K, Montaser-Kouhsari L, Carrasco M, Heeger DJ. When size matters: attention affects performance by contrast or response gain. Nat Neurosci. 2010;13:1554-9. doi: 10.1038/ nn.2669.

13. Guterl S. Is teaching to a student's 'learning style' a bogus idea? Scientific American. 2013 Sept. Available at: https:// www.scientificamerican.com/article/is-teaching-to-a-students-learning-style-a-bogus-idea/. 